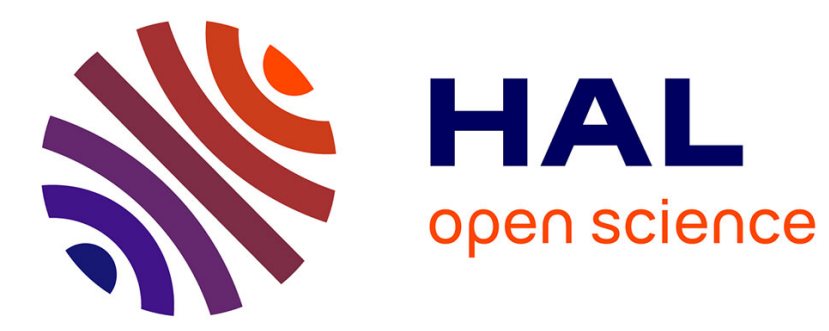

\title{
Regard cliométrique sur les conditions d'une paix réussie
}

Antoine Parent, Vincent Touzé

\section{To cite this version:}

Antoine Parent, Vincent Touzé. Regard cliométrique sur les conditions d'une paix réussie: Conclusion. Revue de l'OFCE, 2021, Centenaire de la promulgation du Traité de Versailles (1920-2020). Regards croisés entre historiens et économistes sur les conséquences de la paix, 1 (171), pp.327-329. 10.3917/reof.171.0327 . hal-03375083

\section{HAL Id: hal-03375083 \\ https://hal-sciencespo.archives-ouvertes.fr/hal-03375083}

Submitted on 12 Oct 2021

HAL is a multi-disciplinary open access archive for the deposit and dissemination of scientific research documents, whether they are published or not. The documents may come from teaching and research institutions in France or abroad, or from public or private research centers.
L'archive ouverte pluridisciplinaire HAL, est destinée au dépôt et à la diffusion de documents scientifiques de niveau recherche, publiés ou non, émanant des établissements d'enseignement et de recherche français ou étrangers, des laboratoires publics ou privés. 


\title{
REGARD CLIOMÉTRIQUE SUR LES CONDITIONS D'UNE PAIX RÉUSSIE
}

\author{
Antoine Parent \\ OFCE, Sciences Po ; Université Paris 8, LED ; \\ Cliometrics And Complexity - IXXI, Complex Systems Institute-Ens Lyon \\ Vincent Touzé \\ Sciences Po, OFCE
}

En Revue de l'OFCE a souligné la richesse et la pluralité des lectures qui peuvent être tirées 100 ans après la promulgation du Traité de Versailles. Faire un bilan sous forme de leçon définitive tirée de I'histoire est un exercice ardu : I'un des écueils majeurs provient du point dans le temps à partir duquel on choisit d'analyser le passé. Par exemple si, comme il est de coutume sur le sujet, on choisit de se situer en 1933 pour juger des conséquences du Traité de paix de 1920, on sera tenté de voir dans l'un la conséquence de l'autre, tombant ainsi sous le coup de l'ineffable biais cognitif post hoc, ergo propter hoc («à la suite de cela, donc à cause de cela »), ce qui constitue le sophisme bien connu et dénoncé par les cliomètres, consistant à prendre pour la cause ce qui n'est qu'un antécédent.

Ce numéro thématique a notamment cherché à analyser une thèse qui fit florès, celle du Traité de Versailles cause de l'avènement du nazisme : la ténacité de la condamnation du Traité de Versailles tient pour partie au texte de Keynes lui-même, « Les conséquences économiques de la paix », qui condamne le Traité de Versailles comme une paix carthaginoise portant en elle les germes d'une terrible dictature à venir, côté vaincu. Cette thèse, à la suite de Keynes (1919), est devenue le conventional wisdom sur le sujet. L'objet de ce numéro a été l'occasion de la discuter en mettant en lumière certaines de ses apories. Les divers éclairages apportés dans ce numéro ont mis en lumière un 
raisonnement historique inverse : post hoc, non est propter hoc, c'est-àdire après cela, mais pas à cause de cela. Que le Traité de Versailles ait été instrumentalisé par Hitler (ce que montre très bien Gerd Krumeich dans son article) ne fait aucun doute, mais ramener l'explication de la montée du nazisme au seul Traité de Versailles (facteur déclencheur) est assurément réducteur si l'on songe à d'autres facteurs explicatifs analysés par exemple par Hannah Arendt dans ses Origines du système totalitaire, comme le pangermanisme, l'antisémitisme, l'idéologie et la terreur. Par ailleurs, l'analyse comparée du mouvement fasciste en Europe dans l'après-guerre montre que la montée des extrêmes a agi comme un phénomène commun aux pays vainqueurs et vaincus de la guerre, que l'on songe aux ligues fascistes en Grande Bretagne et en France, au régime mussolinien en Italie, au franquisme en Espagne. Dès lors, le Traité de Versailles a bon dos pour servir à fustiger le tort des seuls pays vainqueurs.

Nous voudrions dans cette conclusion ouverte essayer de définir les contours de ce que serait l'enseignement cliométrique à retirer du Traité de Versailles et, par extension, de ce que seraient les conditions d'une paix réussie. Pour nous, les leçons cliométriques de la paix se situent principalement à deux niveaux :

1) L'un des objectifs avoués de la cliométrie est de «tuer des mythes » à la vie dure. La thèse du Traité de Versailles cause de l'avènement du nazisme en est assurément un. Or, le Traité de Versailles n'ayant pas été appliqué, l'Allemagne n'ayant pas payé l'intégralité des réparations de guerre imposées par le traité, il est difficile de prétendre que la rigueur de ce dernier fut la cause du ressentiment du vaincu conduisant à l'avènement du nazisme. Un contrefactuel pertinent du Traité de Versailles consisterait tout au contraire à simuler son application, c'est-à-dire l'incidence d'un paiement effectif des réparations par I'Allemagne sur la politique de remilitarisation engagée par Hitler.

L'objectif de la cliométrie doit être d'essayer de restituer les aspirations des acteurs de I'histoire et de comprendre les logiques d'actions du moment. De ce point de vue, pourquoi fait-on si peu de cas dans I'historiographie allemande de ces Allemands qui ont renversé le Reich ? Pourquoi juger de façon si systématique 1919-1920 à l'aune de 1933 et non de 1919-1920 ? Ceci conduit à négliger ou minorer la force du mouvement pacifiste et démocratique allemand entre fin 1918 et la République de Weimar. Il est singulier qu'il ait fallu attendre si longtemps (2018) pour voir la traduction française de l'ouvrage de Sébastien Haffner paru en 1979 Allemagne, 1918 : une révolution trahie. 
Pourtant cet ouvrage restitue les aspirations à la paix des Allemands en 1918 (les marins de la base navale de Kiel en premier lieu), qui ont défendu le principe d'une république démocratique contre le maintien du pouvoir impérial et l'emprise de l'armée sur la société : «Que voulaient les masses révolutionnaires allemandes ? Pas le socialisme, en tout cas pas tout de suite. Aucune usine ne fut occupée en novembre (1918). La première exigence concernait la fin de la guerre et le renversement du pouvoir militaire et de la monarchie (Haffner, 2018, p. 219). L'auteur poursuit : "Cette révolution n'était ni socialiste, ni communiste. Elle était presqu'accessoirement républicaine et pacifiste. Consciemment elle était avant tout antimilitariste... Les masses qui s'étaient donné ces nouveaux organes d'État (les conseils) n'étaient ni spartakistes, ni bolchéviques, mais social-démocrate». Pour Haffner $(1979,2018)$, la tentative de coup d'état du général von Lüttwitz et de Wolfgang Kapp contre la République en mars 1920 est contrée par un mouvement du même acabit : "En cette semaine de grève du 14 au 21 mars 1920, le prolétariat allemand répéta son exploit de la semaine révolutionnaire du 4 au 10 novembre $1918 \ldots$... L'action des masses n'avait pas un caractère socialiste mais démocratique et anti-militariste: la grève générale était dirigée contre un pouvoir militaire et pensait venir en aide, contre ce dernier, au gouvernement civil » (cité par Jean-Louis Panné, 1918 : «Quelle révolution an Allemagne? » in $L^{\prime} O U R S, n^{\circ} 480$ juillet-août 2018). De ces épisodes, la doxa retient la thèse du « coup de poignard dans le dos » qui sera ensuite habilement exploité par Hitler et deviendra l'un des arguments favoris des nazis.

2) La lecture de Haffner soulève un autre intérêt majeur pour le cliomètre quant aux leçons à tirer de I'histoire : comparant 1789 en France à 1917 en Russie et 1918-1920 en Allemagne, l'auteur suggère que les révolutions réussies sont faites en temps de paix, pas en temps de guerre. À cela, nous pouvons ajouter, à la lumière des articles de ce numéro de la Revue de l'OFCE, que les secrets d'une paix réussie passent certainement par la reconnaissance pleine et entière des victoires des démocraties contre les tyrannies et autres régimes autocratiques. Le Traité de Versailles eût connu une autre fin si les acteurs avaient reconnu qu'il était signé entre régimes démocratiques qui mettaient fin à deux empires, allemand et austro-hongrois. Expliquer la réussite d'un traité de paix international par les composantes démocratiques qu'il sait génèrer reste à modéliser pour l'économiste cliomètre. 